\title{
Reproductive isolation between sympatric and allopatric Brazilian populations of Lutzomyia longipalpis s.I. (Diptera: Psychodidae).
}

\author{
Nataly A Souza, Claudia A Andrade-Coelho, Felipe M Vigoder', Richard D Ward², \\ Alexandre A Peixoto ${ }^{1 /+}$ \\ Laboratório de Transmissores de Leishmanioses, 'Laboratório de Biologia Molecular de Insetos, Instituto Oswaldo Cruz-Fiocruz, Av. Brasil \\ 4365, 21045-900 Rio de Janeiro, Brasil ${ }^{2}$ Institute of Science and Technology in Medicine, School of Life Sciences, Keele University, \\ Staffordshire, U.K.
}

Lutzomyia longipalpis s.l., the main vector of Leishmania chagasi in Latin America, is a species complex although the exact number of siblings is yet unknown. In Brazil, the siblings differ in male copulatory courtship songs and pheromones that most certainly act as pre-zygotic reproductive barriers. Here we analysed the reproductive isolation between three allopatric and two sympatric populations of Lu. longipalpis s.l. from Brazil. The results indicate a strong copulatory and pre-mating isolation between the three allopatric populations. In addition, the results also indicate a stronger pre-mating isolation between the two sympatric siblings than between the three allopatric ones, suggesting a role for reinforcement in the speciation of the $\mathrm{Lu}$. longipalpis s.l. complex.

Key words: visceral leishmaniasis - sand flies - species complex - reinforcement

Lutzomyia longipalpis s.l. occurs from Argentina to Mexico (Young \& Duncan 1994) and because of its wide distribution there have been doubts expressed that this taxon is a single species. Mangabeira (1969) commented on morphological variation seen in males. He observed that specimens captured in the state of Pará, North Brazil, bore a single pair of pale tergal spots on abdominal segment IV (1S males) and those captured from the Northeastern state of Ceará (CE) showed an additional pair of spots on segment III (2S males). Mangabeira commented that the two forms were found in different ecological conditions and speculated that they might represent two species. The existence of a complex was confirmed by Ward et al. $(1983,1988)$ and Lanzaro et al. (1993) in crossing experiments, although the male spot phenotype turned out to be only useful as a morphological marker of different species in some localities such as Sobral, CE (see below) (reviewed in Bauzer et al. 2007).

In Brazil, Lutzomyia longipalpis s. l. (Lutz \& Neiva, 1912) is without any doubt the principal vector of American visceral leishmaniasis (AVL). It is present in nearly all of the foci of visceral leishmaniasis, is highly anthropophilic as well as readily feeding on dogs and foxes which act as reservoirs of Leishamania chagasi which are frequently found infected (reviewed in Lainson \& Rangel 2005).

Analysis of male copulatory courtship songs (Souza et al. 2002, 2004) and pheromones (Ward et al. 1988, Hamilton et al. 1996a,b, 2005) have shown that different Brazilian populations of $\mathrm{Lu}$. longipalpis belong to

Financial support: CNPq, Fiocruz (PAPES IV), Howard Hughes Medical Institute

+ Corresponding author: apeixoto@fiocruz.br

Received 21 September 2007

Accepted 14 March 2008 different species. Their sibling species status was also confirmed by the use of molecular markers, such as the behavioural genes period (Bauzer et al. 2002a,b) and cacophony (Bottecchia et al. 2004), and microsatellites (Maingon et al. 2003, Watts et al. 2005). Therefore, there is now no doubt that $L u$. longipalpis s.l. is a species complex in Brazil (reviewed in Bauzer et al. 2007, Maingon et al. 2008), a fact that might have significant epidemiological consequences as sibling species often differ in their importance as vectors.

The best studied populations in Brazil, from an evolutionary point of view, are located in Jacobina (state of Bahía), Lapinha Cave in Lagoa Santa (state of Minas Gerais), Natal (state of Rio Grande do Norte) and Sobral (CE) (Bauzer et al. 2007). The first three localities represent different allopatric siblings (Bauzer et al. 2002b, Bottecchia et al. 2004, Watts et al. 2005) while in Sobral two species coexist in sympatry (Bauzer et al. 2002a, Maingon et al. 2003, Bottecchia et al. 2004). In the present study we compared the reproductive isolation among the three allopatric populations and between the Sobral sympatric siblings.

Initially samples of the populations of Jacobina, Lapinha and Natal were obtained using CDC traps (4 to 9 traps in each locality). All males collected in Lapinha had a single pair of spots (1S) in segment IV and all males from Jacobina were 2S (two pairs in segments III and IV, with similar sizes). The majority of males from Natal had the intermediate phenotype, with the extra pair in segment III with less than $3 / 4$ of the size of the spots in segment IV (see Ward et al. 1988). The population from Natal is highly polymorphic for the male spot phenotype but in this locality there is no evidence for the existence of sympatric sibling species (Mukhopadhyay et al. 1998, Bauzer et al. 2002b, Bottecchia et al. 2004, Watts et al. 2005). Eggs from 100 to 200 wild-caught females from each of the three localities were used to establish laboratory colonies following the methodologies 
of Rangel et al. (1985) and Souza et al. (1999). Crossing experiments (see below) were carried out using mainly sand flies from the F2 and F3 generations. After these initial crosses three new samples from each locality were obtained to boost the colonies and new crossing experiments were carried out after each new collection.

The establishment of colonies of the two sympatric populations of Sobral occurred more than one year after the end of the crossing experiments with allopatric populations. By this time the three original allopatric colonies were no longer available. Sobral is one of the few localities were the number of male tergal spots (1S or $2 \mathrm{~S}$ ) can be used to separate sympatric siblings (Ward et al. 1988, Bauzer et al. 2002a, Maingon et al. 2003). Sand flies were collected using $9 \mathrm{CDC}$ traps in three different houses, distant approximately 3-11 km from each other. Initially more than 170 isofemale lines (IL) were established from wild caught females. These IL were sorted according to the number of spots in their F1 males. A few lines $(\sim 4 \%)$ exhibiting ambiguous intermediate phenotypes (Ward et al. 1988) were observed and discarded before colony establishment. $1 \mathrm{~S}$ and $2 \mathrm{~S}$ colonies were established and maintained from the sorted IL $(\sim 34 \%$ $1 \mathrm{~S}$ and $\sim 62 \% 2 \mathrm{~S}$ ) as described in Rangel et al. (1985) and Souza et al. (1999). The initial crosses were carried out using mainly the F2 and F3 generations of these two colonies. As before, three new samples were obtained from Sobral to boost the colonies and new crosses were carried out after each new collection.

For the crossing experiments pupae were separated in individual vials before emergence so males and females were virgin when they were used in the crosses. Sand flies 5-7-day old were used in the experiments. One male and one blood-fed female were placed together in a small mating chamber ( $15 \mathrm{~mm} \times 10 \mathrm{~mm} \times 5 \mathrm{~mm}$ ) for up to $20 \mathrm{~min}$. If no copulation occurred in $20 \mathrm{~min}$ the couple was discarded and replaced until a total of 25 copulations were observed for each cross. Heterospecific and homospecific crosses were usually carried out in parallel. The females that copulated were individualized again in oviposition vials and post blood-feeding egg hatching was monitored.
Table I shows the number of attempted crosses, the percentage of copulations observed, the percentage of females that laid eggs before dying and the percentage of those that produced larvae in crosses between the three allopatric populations. The results show that all females that were mated to homospecific males and survived long enough to lay eggs produced viable larvae. On the other hand none of the heterospecific crosses yield progeny. Table II shows similar results for crossing experiments carried out with the sympatric siblings of Sobral. As before, all females that were mated to homospecific males, and that did not die before laying eggs, successfully produced larvae. Similar results were obtained by Ward et al. $(1983,1988)$ who observed insemination failure in copulations between males and females of some Brazilian populations, including the Sobral siblings. Interestingly enough, Lu. Longipalpis s.l. males produce copulatory "lovesongs" (Souza et al. 2002, 2004) and pheromones (Hamilton et al. 1996a,b, 2005, Casanova et al. 2006) that show striking differences between populations suggesting that those acoustic and chemical signals have a role in the observed insemination failures.

The results presented in Table I and II also show evidence for pre-mating reproductive isolation as summarized in the Figure. While copulations were observed in nearly half of the attempted homospecific crosses $(0.465 \pm 0.042)$, only about $25 \%(0.258 \pm 0.030)$ of copulations were observed in heterospecific crosses among allopatric populations. This difference is highly significant $(t=4.125$; d.f. $=9 ; \mathrm{p}<0.01$; after arcsine transformation) and indicates pre-mating reproductive isolation. Moreover, the results obtained with the heterospecific crosses involving the two sympatric populations of Sobral indicate an even stronger pre-mating isolation between the two siblings in this locality as no copulations were observed in a total of 179 crosses. The difference between sympatric and allopatric heterospecific crosses is also highly significant $(t=8.56$; d.f. $=6 ; \mathrm{p}<0.001$; after arcsine transformation).

Analysis of the divergence and gene flow among Brazilian populations using a number of different mark-

TABLE I

Reproductive isolation between allopatric populations of $\mathrm{Lu}$. longipalpis

\begin{tabular}{|c|c|c|c|c|}
\hline Type of cross & $\begin{array}{l}\text { Attempted crosses } \\
\text { (n) }\end{array}$ & $\begin{array}{c}\text { Copulations } \\
(\%)\end{array}$ & $\begin{array}{c}\text { Mated females laying } \\
\text { eggs before dying } \\
(\%)\end{array}$ & $\begin{array}{c}\text { Females producing larvae } \\
(\%)\end{array}$ \\
\hline \multicolumn{5}{|l|}{ homospecific } \\
\hline ㅇ Jac x $\widehat{\varnothing} \mathrm{Jac}$ & 62 & 40.3 & 84.0 & 100 \\
\hline ○ Lap x $\widehat{\partial}$ Lap & 50 & 50.0 & 76.0 & 100 \\
\hline o Nat x $\delta$ Nat & 41 & 61.0 & 56.0 & 100 \\
\hline \multicolumn{5}{|l|}{ heterospecific } \\
\hline$\Varangle$ Lap x $\widehat{\sigma} \mathrm{Jac}$ & 123 & 20.3 & 64.0 & 0 \\
\hline o Nat $\mathrm{x} \delta \mathrm{Jac}$ & 78 & 32.1 & 68.0 & 0 \\
\hline o Jac x $\precsim$ Lap & 126 & 19.8 & 56.0 & 0 \\
\hline o Nat x $\delta$ Lap & 117 & 21.4 & 68.0 & 0 \\
\hline o Jac x $\widehat{\varnothing} \mathrm{Nat}$ & 66 & 37.9 & 72.0 & 0 \\
\hline q Lap x $\widehat{\sigma} \mathrm{Nat}$ & 108 & 23.1 & 60.0 & 0 \\
\hline
\end{tabular}

$a$ : only females that laid eggs were considered. Jac: Jacobina; Lap: Lapinha; Nat: Natal 
TABLE II

Reproductive isolation between sympatric populations of Lu. longipalpis

\begin{tabular}{|c|c|c|c|c|}
\hline Type of cross & $\begin{array}{l}\text { Attempted crosses } \\
\text { (n) }\end{array}$ & $\begin{array}{l}\text { Copulations } \\
\text { (\%) }\end{array}$ & $\begin{array}{c}\text { Mated females laying } \\
\text { eggs before dying } \\
(\%)\end{array}$ & $\begin{array}{c}\text { Females producing larvae } a \\
(\%)\end{array}$ \\
\hline \multicolumn{5}{|l|}{ homospecific } \\
\hline † Sob1S x $ð$ Sob1S & 58 & 43.1 & 76.0 & 100 \\
\hline $\begin{array}{l}\text { Q Sob2S x } \curvearrowright \text { Sob2S } \\
\text { heterospecific }\end{array}$ & 66 & 37.9 & 68.0 & 100 \\
\hline q Sob2S x ô Sob1S & 98 & 0 & - & - \\
\hline O Sob1S x $\widehat{\jmath}$ Sob2S & 81 & 0 & - & - \\
\hline
\end{tabular}

$a$ : only females that laid eggs were considered. Sob1S: Sobral 1 spot sibling; Sob2S: Sobral 2 spot sibling.

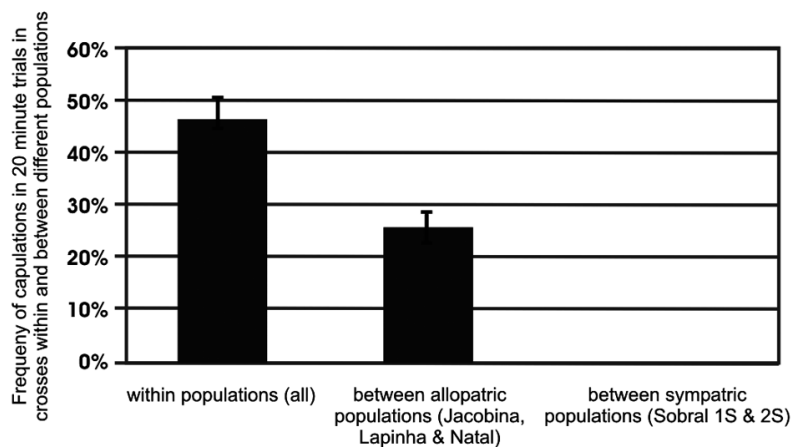

Comparison of pre-mating isolation between Lutzomyia longipalpis s.l. allopatric and sympatric populations.

ers suggest a recent speciation process with the possible occurrence of introgression events (Bauzer et al. 2002a,b, Maingon et al. 2003, Bottecchia et al. 2004, Watts et al. 2005). The fact that sympatric siblings show stronger pre-mating isolation than the allopatric populations suggests that reinforcement of reproductive isolation (reviewed in Servedio \& Noor 2003) might have had a role in the speciation of Lu. longipalpis complex siblings in Brazil. We are currently expanding our population genetic analysis of this complex to other populations. It will be interesting to extend these crossing experiments to other areas where sympatric siblings might be found to determine how widespread the occurrence of enhanced pre-mating isolation is in these populations when compared to allopatric siblings.

\section{ACKNOWLEDGMENTS}

To Maria de Lurdes dos Santos (IOC-Fiocruz) for technical assistance in the Insectary, and Luiz Henrique Costa (IOCFiocruz), Lindenberg de Souza (Secretaria de Saúde do Estado do Ceará), Iraci Duarte (Secretaria Estadual de Saúde Pública do Rio Grande do Norte), Arlinete Medeiros (Secretaria Estadual de Saúde Pública do Rio Grande do Norte), Ítalo Sherlock (CPqGM-Fiocruz) and Reginaldo Brazil (IOC-Fiocruz) for assistance with the sand fly field collections.

\section{REFERENCES}

Bauzer LG, Gesto JS, Souza NA, Ward RD, Hamilton JG, Kyriacou $\mathrm{CP}$, Peixoto AA 2002a. Molecular divergence in the period gene between two putative sympatric species of the Lutzomyia longipalpis complex. Mol Biol Evol 19: 1624-1627.
Bauzer LGSR, Souza NA, Ward RD, Kyriacou CP, Peixoto AA 2002b. The period gene and genetic differentiation between three Brazilian populations of Lutzomyia longipalpis. Insect Mol Biol 11: 315-323.

Bauzer LG, Souza NA, Maingon RD, Peixoto AA 2007. Lutzomyia longipalpis in Brazil: a complex or a single species? A minireview. Mem Inst Oswaldo Cruz 102: 1-12.

Bottecchia M, Oliveira SG, Bauzer LG, Souza NA, Ward RD, Garner KJ, Kyriacou CP, Peixoto AA 2004. Genetic divergence in the cacophony IVS6 intron among five Brazilian populations of Lutzomyia longipalpis. J Mol Evol 58: 754-761.

Casanova C, Hamilton JG, Trigo JR, Costa AI 2006. Identification of sex pheromones of Lutzomyia longipalpis (Lutz \& Neiva, 1912) populations from the state of São Paulo, Brazil. Mem Inst Oswaldo Cruz 101: 113-115.

Hamilton JGC, Dawson GW, Pickett JA 1996a. 9-Methylgermacrene-B: Proposed structure for novel homosesquiterpene from the sex pheromone glands of Lutzomyia longipalpis (Diptera: Psychodidae) from Lapinha, Brazil. J Chem Ecol 22: 1477-1491.

Hamilton JGC, Dawson GW, Pickett JA 1996b. 3-methyl-alphahimachalene: Proposed structure for novel homosesquiterpene sex pheromone of Lutzomyia longipalpis (Diptera: Psychodidae) from Jacobina, Brazil. J Chem Ecol 22: 2331-2340.

Hamilton JGC, Maingon RDC, Alexander B, Ward RD, Brazil RP 2005. Analysis of the sex pheromone extract of individual male Lutzomyia longipalpis sandflies from six regions in Brazil. Med Vet Entomol 19: 480-488.

Lainson R, Rangel EF 2005. Lutzomyia longipalpis and the eco-epidemiology of American visceral leishmaniasis, with particular reference to Brazil: a review. Mem Inst Oswaldo Cruz 100: 811-827.

Lanzaro GC, Ostrovska K, Herrero MV, Lawyer PG, Warburg A 1993. Lutzomyia longipalpis is a species complex: genetic divergence and interspecific hybrid sterility among three populations. Am J Trop Med Hyg 48: 839-884.

Lutz A, Neiva A 1912. Contribuição para o conhecimento das espécies do gênero Phlebotomus existentes no Brasil. Mem Inst Oswaldo Cruz 4: 82-95.

Maingon RD, Ward RD, Hamilton JG, Bauzer LG, Peixoto AA 2008. The Lutzomyia longipalpis species complex: does population substructure matter to Leishmania transmission? Trends Parasitol 24: $12-17$.

Maingon RD, Ward RD, Hamilton JG, Noyes HA, Souza N, Kemp SJ, Watts PC 2003. Genetic identification of two sibling species of Lutzomyia longipalpis (Diptera: Psychodidae) that produce distinct male sex pheromones in Sobral, Ceara State, Brazil. Mol Ecol 12: 1879-1894. 
Mangabeira Filho O 1969. Sôbre a sistemática e biologia dos Phlebotomus do Ceará. Rev Bras Mal Doenc Trop 21: 3-26.

Mukhopadhyay J, Ghosh K, Azevedo AC, Rangel EF, Munstermann LE 1998. Genetic polymorphism of morphological and biochemical characters in a Natal, Brazil, population of Lutzomyia longipalpis (Diptera: Psychodidae). J Am Mosq Control Assoc. 14: 277-282.

Rangel EF, Souza NA, Wermelinger ED, Barbosa AF 1985. Estabelecimento de colônia de Lutzomyia intermedia (Lutz \& Neiva, 1912) (Diptera, Phychodidae, Phlebotominae). Mem Inst Oswaldo Cruz 80: 219-226.

Servedio MR, Noor MAF 2003. The role of reinforcement in speciation: Theory and data. Ann Rev Ecol Evol Syst 34: 339-364.

Souza NA, Andrade-Coelho CA, Vilela ML, Barbosa AF, Rangel EF 1999. A new larval diet for colonization of Phlebotominae sand flies. Mem Inst Oswaldo Cruz 94: 845-847.

Souza NA, Vigoder FM, Araki AS, Ward RD, Kyriacou CP, Peixoto AA 2004. Analysis of the copulatory courtship songs of Lutzomyia longipalpis in six populations from Brazil. J Med Entomol 41: 906-913.

Souza NA, Ward RD, Hamilton JGC, Kyriacou CP. Peixoto AA 2002.
Copulation songs in three siblings of Lutzomyia longipalpis (Diptera: Psychodidae). Trans R Soc Trop Med Hyg 96: 102-103.

Ward RD, Ribeiro AL, Ready PD, Murtagh A 1983. Reproductive isolation between different forms of Lutzomyia longipalpis (Lutz \& Neiva, 1912), (Diptera: Psychodidae) the vector of Leishmania donovani chagasi Cunha \& Chagas and its significance to kalaazar distribution in South America. Mem Inst Oswaldo Cruz 78: 269-280.

Ward RD, Phillips A, Burnet B, Marcondes CB 1988. The Lutzomyia longipalpis complex: reproduction and distribution. In: Biosystematics of haematophagous Insects, MW Service (ed.), Systematics Association Special, Vol. 37, Clarendon Press, Oxford, p. 257-269.

Watts PC, Hamilton JG, Ward RD, Noyes HA, Souza NA, Kemp SJ, Felliciangeli MD, Brazil RP, Maingon RD 2005. Male sex pheromones and the phylogeographic structure of Lutzomyia longipalpis species complex (Diptera: Psychodidae) from Brazil and Venezuela. Am J Trop Med Hyg 73: 734-743.

Young DG, Duncan NA 1994. Guide to the identification and geographic distribution of Lutzomyia sandflies in Mexico, the West Indies, Central and South America Diptera: Psychodidae). Mem Am Entomol Inst 54: 1-881. 